\title{
GROWTH, CANNIBALISM, AND SURVIVAL RELATIONS IN LARVAE OF EUROPEAN CATFISH, SILURUS GLANIS (ACTINOPTERYGII: SILURIFORMES: SILURIDAE)- ATTEMPTS TO MITIGATE SIBLING CANNIBALISM
}

\author{
Jarosław KRÓL ${ }^{1 *}$, Wojciech FLISIAK ${ }^{1}$, Piotr URBANOWICZ ${ }^{1}$, \\ and Dariusz ULIKOWSKI ${ }^{2}$ \\ ${ }^{1}$ Department of Ichthyology, University of Warmia and Mazury in Olsztyn, Poland \\ ${ }^{2}$ Department of Sturgeon Fish Breeding, Inland Fisheries Institute in Olsztyn, Poland
}

\begin{abstract}
Król J., Flisiak W., Urbanowicz P., Ulikowski D. 2014. Growth, cannibalism, and survival relations in larvae of European catfish, Silurus glanis (Actinopterygii: Siluriformes: Siluridae)—attempts to mitigate sibling cannibalism. Acta Ichthyol. Piscat. 44 (3): 191-199.
\end{abstract}

\begin{abstract}
Background. Under culture conditions, intra-cohort cannibalism is one of the main factors that affects the growth and survival of fishes, especially during the early life stages of carnivorous species. Cannibalism is chiefly influenced by environmental factors, but parental effects cannot be excluded. The complete elimination of cannibalism in the larviculture of carnivorous fish species is virtually impossible, but it may be possible to mitigate its impact through a better understanding of the extrinsic and intrinsic factors that affect the intensity of cannibalism. The presently reported study had two complementary objectives: a) it examined how the growth-cannibalism-survival dynamics in cultured larvae of European catfish, Silurus glanis Linnaeus, 1758, is affected by maternal influence, and b) it evaluated the possibility of reducing cannibalism while supplementing food with tryptophan (TRP), which is a precursor of serotonin that has a becalming effect on fish.

Materials and methods. Two 30 -day experiments were conducted $\left(0 \mathrm{~L}: 24 \mathrm{D}, 26.5-27.0^{\circ} \mathrm{C}\right)$. In the first experiment, 3-day old larvae of European catfish originating from four female parents (f1, f2, f3, and f4) were cultured in full siblings groups. In the second experiment, larvae from all four progenies were reared together and fed commercial diets supplemented with different doses of tryptophan (T0, T1, T2). Fish mortality including cannibalism, growth, and biomass were estimated every 10 days during both experiments.

Results. In both experiments, cannibalism was the main cause of mortality and losses to type II (complete) cannibalism were higher than those caused by type I (incomplete) cannibalism. No maternal influence on cannibalistic behaviour was found. Tryptophan supplementation had no significant effect on fish growth or survival.

Conclusion. The results of presently reported studies confirmed that cannibalism is an important factor affecting survival in larviculture of European catfish. Controlled conditions used in initial rearing of European catfish larvae, significantly enhanced the survival of juvenile catfish in comparison to traditional pond culture.
\end{abstract}

Keywords: European catfish, larvae, cannibalism, culture conditions, maternal effect, tryptophan

\section{INTRODUCTION}

Increased interest in aquaculture of the European catfish, Silurus glanis Linnaeus, 1758, in recent years resulted from both, good nutritional value of the flesh and implementation of improved or new technologies on catfish culture (Linhart et al. 2002). Efficient production of European catfish larvae require controlled conditions, especially during the initial rearing phase. The survival rates of larvae, directly cultured in ponds, usually not exceed several percent (Ulikowski and Borkowska 1999). In predatory fish larviculture, intra-cohort cannibalism has a major impact on survival, especially during the first rearing weeks (Loadman et al. 1986, Katavić et al. 1989, Baras 1999, 2013). Cannibalism is facilitated by growth dispersal, which enables large fish to prey on smaller individuals. It has also been proposed that some fish are just "natural born killers" with a greater propensity to exert cannibalism than others (Baras and Jobling 2002). Nevertheless in most instances, cannibalism corresponds to an alternative feeding strategy, directly or indirectly influenced by environmental factors rather than by any genetic component (Hecht and Pienaar 1993, Svenning and Borgstrøm 2005, Baras and Jobling 2002, Baras 2013). However, the effect of intrinsic-genetic factors on canni-

\footnotetext{
* Correspondence: Dr Jarosław Król, Katedra Ichtiologii, Uniwersytet Warmińsko Mazurski w Olsztynie, ul. Warszawska 117A, 10-718 Olsztyn, Poland, phone/fax: +48 8952337 54; e-mail (JK): krolas@uwm.edu.pl.
} 
balism cannot be excluded in absence of experimental studies (Thibault 1974, Baras et al. 2014).

Cannibalism is mainly governed by size dispersal among larvae. During the early life stages, when the size heterogeneity of larvae is low, type I cannibalism (partial and tail-first ingestion) occurs (Cuff 1980, Baras and Jobling 2002, Baras 2013). Later, as size heterogeneity increases, type I cannibalism is replaced by type II cannibalism, which is characterized by total prey ingestion and gapesize limitations (Cuff 1980, Hecht and Appelbaum 1988, Hecht and Pienaar 1993, Baras 1999, Baras et al. 2000, 2003). Growth dynamics of a cohort of larvae is usually affected by multiple interactive and non-interactive factors such as environment and population structure, respectively (Kestemont et al. 2003). Baras and Jobling (2002) identified several population factors, as well as extrinsic factors (environmental structure, temperature, light intensity, food availability, and food quality) that regulate size heterogeneity and cannibalism in fishes. However, effects of intrinsic factors - including maternal or paternal effectson growth heterogeneity (which is the main cause of cannibalism) in larval or juvenile stages, have been showed in several species (Saillant et al. 2001, Babiak et al. 2004, Butts and Litvak 2007, Ottesen and Babiak 2007, Adamek et al. 2011, Nuñez et al. 2011).

To date, attempts to mitigate cannibalism in larviculture have mainly focused on routine size grading, environmental and population factors, or food quantity and quality, with special emphasis to weaning schedules (from live food to formulated diets). An alternative could be using dietary factors that reduce cannibalistic behaviour. Tryptophan (TRP) is a precursor of serotonin (5-HT), which is known to reduced aggression in vertebrates, including fishes. Increased TRP content in the feed enhances fish brain serotonergic activity with stress-releasing effects (Johnston et al. 1990, de Pedro et al. 1998, Winberg et al. 2001, Lepage et al. 2002) or decreased aggressive behaviour (Winberg et al. 2001, Hseu et al. 2003, Höglund et al. 2005). However, relatively high levels of serotonin tend to limit food intake in fish (de Pedro et al. 1998, Hseu et al. 2003, Papoutsoglou et al. 2005a).

The presently reported study aimed to investigate potential maternal influence on cannibalism, growth, and survival in European catfish larvae. In a second experiment, the potential effects of dietary tryptophan supplementation on growth-cannibalism-survival dynamics were examined.

\section{MATERIALS AND METHODS}

Fish. The larvae used in both experiments originated from the artificial reproduction of captive broodfish belonging to the Department of Sturgeon Fish Breeding of the Inland Fisheries Institute in Olsztyn, Poland. Four separate batches of eggs, originating from four female fish (Table 1) were fertilized by the "dry method" using semen from the same male and were incubated in four Weiss jars at 23.0 $\pm 1.0^{\circ} \mathrm{C}$ until hatching $(48 \mathrm{~h})$. Fifty eggs were randomly sampled from each female and digital images were taken (before and $24 \mathrm{~h}$ after fertilization) for analysis of egg diameter. Larvae were kept in separate hatching tanks (100 L volume) for the next 2 days before the onset of the both experiments.

Design of Experiment 1. On day 3 post-hatching (considered as the day 0 of the experiment), four experimental groups of full siblings (f1, f2, f3, and f4) were set in triplicate. These larvae were cultured in glass aquaria with a volume of $6 \mathrm{~L}$ each, in an indoor water recirculating system. Each aquarium was stocked with 120 larvae (with the density of 20 larvae $\cdot \mathrm{L}^{-1}$ ).

Design of Experiment 2. Two commercial diets, Perla Larva Proactive 5.0 (Trouvit Nutreco Holland) and Aller Futura EX Gr2 (Aller Aqua, Denmark) were used for preparing the experimental diets $(\mathrm{T} 1, \mathrm{~T} 2)$ and as the control diet (T0). Formulated diets contained $62 \%$ and $64 \%$ protein, $11 \%$ and $12 \%$ lipid, and $10 \%$ and $5 \%$ carbohydrates for first and second diet, respectively and both were recommended for catfish larvae and juveniles. Supplemented diets were prepared by the sprinkle method, containing $10 \mathrm{~g} \mathrm{TRP} \cdot \mathrm{kg}^{-1}$ (T1) and $20 \mathrm{~g} \mathrm{TRP} \cdot \mathrm{kg}^{-1}$ (T2). The TRP (crystalline L-tryptophan, Sigma, USA) of each treatment was weighed, dissolved in hot water plus ethanol, then sprinkled on the commercial diet and vaporized using vacuum chamber (AGA Labor, Lublin, Poland). The diets were dried at room temperature and stored at $-20^{\circ} \mathrm{C}$ before use. To avoid palatability effect, T0 was sprinkled with ethanol solution without addition of tryptophan. In the same time as in Experiment 1, the remaining larvae, originating from four females, were mixed and randomly divided in three experimental groups (T0, T1, and T2; also in triplicate). Experiment 2 was conducted in the twin recirculation system with the same density of larvae as described in Experiment 1.

Table 1

Characteristics of females of European catfish, Silurus glanis, and diameter of their eggs

\begin{tabular}{ccccc}
\hline \multirow{2}{*}{ Female } & \multirow{2}{*}{$\begin{array}{c}\text { Body } \\
\text { weight }[\mathrm{g}]\end{array}$} & GSI [\%] & Egg diameter [mm] \\
\cline { 4 - 5 } & 3412 & 17.76 & $2.35 \pm 0.21$ & $3.43 \pm 0.09$ \\
f1 & 2773 & 15.07 & $2.28 \pm 0.09$ & $3.25 \pm 0.07$ \\
f3 & 3266 & 21.06 & $2.49 \pm 0.11$ & $3.49 \pm 0.27$ \\
f4 & 3876 & 13.47 & $2.27 \pm 0.13$ & $3.30 \pm 0.05$ \\
\hline
\end{tabular}

Egg diameter values are mean \pm standard deviation. 
Experimental trials. All other experimental settings and measurements were the same for both experiments. Before the experiments, 30 larvae from each experimental group were sacrificed by using an overdose of anaesthetic (2-phenoxyethanol; $2 \mathrm{~mL} \cdot \mathrm{L}^{-1}$ ) then individually weighed (to the nearest $0.0001 \mathrm{~g}$ ). Both experiments lasted 30 days. Larvae were fed exclusively Artemia nauplii for the first 3 days of the experiment. Then, they were gradually switched to a dry food (Perla Larva Proactive 5.0). After 7 days, fish were fed exclusively dry food (from 20 day, Perla Larva Proactive 5.0 was replaced by Aller Futura EX Gr2). During the first 10 rearing days larvae were fed ad libitum four times a day $(0900,1200,1500$, and $1800 \mathrm{~h})$. From day 10 through day 20 , the daily food ration was set at $30 \%$ of the stock biomass. In the last 10 rearing days this ration was reduced to $18 \%$ of the stock biomass. The photoperiod was set at 0L : 24D. Water temperature, oxygen concentration, and $\mathrm{pH}$ were measured daily (Table 2). Intermediate weight measurements ( $n=15$ in each tank) were taken on days 10 and 20. In both cases, fish were sacrificed for weighing and not returned to the tanks. On the same days all survivors were counted in each tank. Dead fish were removed daily and ranked as truncated (posterior damaged or tailedoff) or non-truncated: starving, intact, or with traces of bites on the abdomen or head. Truncated individuals were considered as victims of type I cannibalism and non-truncated fish as deaths from other causes (Baras et al. 2003). At the end of the experiments all survivors per tank were counted and weighed. Missing fish were considered as victims of type II cannibalism. Coefficients of variation in body weight [\%], were calculated for each day of measurement $\left(\mathrm{CV}^{0}, \mathrm{CV}^{10}, \mathrm{CV}^{20}\right.$, and $\left.\mathrm{CV}^{30}\right)$ based on the formula:

$$
\mathrm{CV}=100 \cdot \mathrm{SD}_{W} \cdot W^{-1}
$$

where $W$ is the average body weight and $\mathrm{SD}_{W}$ is the standard deviation of body weight.

Specific growth rates (SGR) $\left[\% \mathrm{day}^{-1}\right]$, were calculated for each measurement day $\left(\mathrm{SGR}^{0-10}, \mathrm{SGR}^{11-20}\right.$, and $\mathrm{SGR}^{21-30}$ ) based on the formula:

$$
\mathrm{SGR}=100 \cdot\left(\operatorname{Ln} W_{2}-\operatorname{Ln} W_{1}\right) \cdot t^{-1}
$$

where $W_{1}$ and $W_{2}$ are initial and final average body weight between measurements [g] and $t$ is the time interval between weight measurements. The total SGR $\left(\mathrm{SGR}^{0-30}\right)$ over the entire rearing period was also calculated.

Statistical analyses. Egg size, growth, mortalities, survival, and biomass were compared using one-way ANOVA. Normality of parameters distribution was tested by Kolmogorov-Smirnov test. The data expressed in percentages were Arcsin transformed prior to statistical analysis. Significance of differences between groups was estimated using a post hoc Duncan's multiple range. For the comparison of CV values, a non-parametric Kruskal-Wallis test was used. Multiple-regression analysis was used to estimate relations between egg size, growth parameters, all types of mortalities, and survival ( $r$ correlation coefficient). Null hypotheses were rejected at $P<0.05$. Analyses were performed using Statistica software (StatSoft).
Ethical issues. The experiments have been carried out in accordance with regulations of the Animal Ethics Committee in Olsztyn, Poland.

\section{RESULTS}

Experiment 1. There were no significant differences between the egg diameters of the four spawns, neither before nor after fertilization (Table 1). No effect of egg size on the initial body weight of larvae was observed. The initial body weight $\left(W^{0}\right)$ of larvae originating from the four different females did not differ among groups and averaged $0.014 \mathrm{~g}$ (Table 3). At the end of the experiment (day 30$)$, the mean body weight in $\mathrm{f} 4(1.79 \mathrm{~g})$ was significantly lower than in $\mathrm{f} 2$ (2.26 g), while other progenies had intermediate results (Table 3 ). By contrast, there was no effect of maternal origin on intermediate body weights and the specific growth rate (SGR) did not differ among all experimental groups (Table 3). Size dispersal (CV of body weight) increased by about a 3 -fold margin between the beginning and the end of experiment, but it did not differ among maternal origin (Table 3 ).

In every situation losses to type II cannibalism were higher than those by type I cannibalism, whatever the maternal origin (Fig. 1). Type II cannibalism in the last ten days of the experiment was significantly higher than in the preceding days, whereas mortality caused by type I cannibalism was similar throughout the experiment (Fig. 2a, b). The average final survival rates varied from $62.6 \%$ to $71.6 \%$ and did not differ as a function of maternal origin (Table 3 ). In contrast to the situation with type I cannibalism (which is independent upon the extent of size dispersal), type II cannibalism significantly and negatively impacted final survival $\left(r=-0.93 ; F^{*}=38.44 ; P<0.01\right)$. Situations where type II cannibalism was more intense resulted in higher average body weight $(r=0.75 ; F=7.76 ; P=0.01)$, because the predation by large individuals resulted in the removal of the smallest individuals, and thus in a larger size of survivors. Mortalities due to other causes than cannibalism were infrequent, they did not differ among groups (Fig. 1) and they did not affect final survival differently $(P>0.05)$. Experiment 2. Over the entire experiment, the average body weight of fish increased from $0.013 \mathrm{~g}$ (day 0) to more than $1.6 \mathrm{~g}$ (day 30). Size dispersal (CV body weight) increased by a three-fold margin during the experiment

Table 2

Water parameters during 30 days of rearing of European catfish, Silurus glanis, in Experiment 1 and Experiment 2

\begin{tabular}{lcc}
\hline Water parameters & Experiment 1 & Experiment 2 \\
\hline Temperature $\left[{ }^{\circ} \mathrm{C}\right]$ & $26.8 \pm 0.6$ & $26.5 \pm 0.5$ \\
$\begin{array}{l}\text { Oxygen concentration } \\
{\left[\mathrm{mg} \cdot \mathrm{L}^{-1}\right]}\end{array}$ & $7.12 \pm 0.53$ & $6.64 \pm 0.42$ \\
$\mathrm{pH}$ & $7.65 \pm 0.48$ & $8.13 \pm 0.21$ \\
\hline
\end{tabular}

Values are mean \pm standard deviation.

\footnotetext{
*Value of Fisher's test.
} 
(Table 4). There were no significant effects of food supplementation with TRP on final and intermediate body weights, biomasses or size dispersal (Table 4).

As during the first experiment, type II cannibalism was the main cause of mortality here, but the contribution of type I cannibalism was proportionally higher than during Experiment 1 (Fig. 3). The intensity of type I cannibalism was affected by the TRP content, but exclusively during the first 10 days of the experiment, when the highest mortality was observed in group T2 (Fig. 4a). In the following days, differences between groups were no longer significant (Figs. 3 and 4a). Type II cannibalism was not affected by TRP content at any age (Figs. 3 and 4b). In Experiment 2 just like in Experiment 1, type II cannibalism during the last ten rearing days was significantly higher than in the preceding days (Fig. 4b). The average survival at the end of Experiment 2 did not differ among groups (Table 4). Mortality caused by both types of cannibalism (I and II) significantly and negatively affected the final survival $(r=-0.89 ; F=9.77 ; P<0.01)$. Mortalities due to other causes were significantly higher in T2 group than others (Fig. 1) but had no major impact on final survival $(P>0.05)$.

\section{DISCUSSION}

Maternal effects. Larval growth or size heterogeneity both impact substantially the cannibalistic behaviour in young fishes, especially in predatory species with large gape (Baras and Jobling 2002, Baras 2013). Several factors may contribute to larval growth, including genetic effects (at both parental and population levels), and nongenetic effects (such as maternal non-genetic contributions and environmental conditions; Saillant et al. 2001, Butts and Litvak 2007, Ottesen and Babiak 2007, Donelson et al. 2009, Nuñez et al. 2011). A clear impact of parentage on larval growth or size heterogeneity has been found in several species: Atlantic herring, Clupea harengus Linnaeus, 1758 (see Panagiotaki and Geffen 1992); European sea bass, Dicentrarchus labrax (Linnaeus, 1758) (see Saillant et al. 2001); Atlantic halibut, Hippoglossus hippoglossus (Linnaeus, 1758) (see Ottesen and Babiak 2007); and Amazonian catfish, Pseudoplatystoma punctifer (Castelnau, 1855) (see Nuñez et al. 2011). In the presently reported study a weak but significant female effect was observed on the growth of the European catfish larvae but not on size heterogeneity. Differences in early growth of larvae in relation to maternal contribution have often been related to egg size in several fish species, including Atlantic salmon, Salmo salar

Table 3

Growth, size dispersal, survival, and mortality caused by cannibalism of larvae of European catfish,

Silurus glanis, originating from four different females (Experiment 1) during 30 days of rearing

\begin{tabular}{lcccc}
\hline \multirow{2}{*}{ Parameter } & \multicolumn{3}{c}{ Maternal fish } \\
\cline { 2 - 5 } & $\mathrm{f} 1$ & $\mathrm{f} 2$ & $\mathrm{f} 3$ & $\mathrm{f} 4$ \\
\hline$W^{0}$ & $0.0138 \pm 0.0016$ & $0.0140 \pm 0.0016$ & $0.0153 \pm 0.0019$ & $0.0139 \pm 0.0012$ \\
$W^{10}$ & $0.095 \pm 0.023$ & $0.101 \pm 0.007$ & $0.097 \pm 0.004$ & $0.101 \pm 0.005$ \\
$W^{20}$ & $0.56 \pm 0.11$ & $0.54 \pm 0.05$ & $0.52 \pm 0.04$ & $0.53 \pm 0.12$ \\
$W^{30}$ & $1.90^{\mathrm{ab}} \pm 0.40$ & $2.26^{\mathrm{a}} \pm 0.37$ & $1.96^{\mathrm{ab}} \pm 0.18$ & $1.79^{\mathrm{b}} \pm 0.41$ \\
$B^{0}$ & 1.798 & 1.824 & 1.993 & 1.790 \\
$B^{10}$ & $12.12 \pm 3.17$ & $13.01 \pm 1.08$ & $12.21 \pm 0.61$ & $12.68 \pm 0.45$ \\
$B^{20}$ & $54.47 \pm 11.41$ & $57.75 \pm 2.45$ & $51.60 \pm 3.89$ & $56.18 \pm 11.06$ \\
$B^{30}$ & $116.9^{\mathrm{b}} \pm 15.8$ & $149.4^{\mathrm{a}} \pm 11.9$ & $122.3^{\mathrm{ab}} \pm 2.9$ & $118.5^{\mathrm{b}} \pm 9.3$ \\
$\mathrm{CV}^{0}$ & 12.17 & 11.76 & 12.51 & 8.88 \\
$\mathrm{CV}^{10}$ & $27.61 \pm 14.14$ & $25.54 \pm 6.52$ & $29.69 \pm 9.14$ & $32.58 \pm 1.01$ \\
$\mathrm{CV}^{20}$ & $43.23 \pm 5.34$ & $44.18 \pm 3.39$ & $45.60 \pm 13.34$ & $37.55 \pm 7.38$ \\
$\mathrm{CV}^{30}$ & $42.93 \pm 14.47$ & $54.35 \pm 8.19$ & $53.87 \pm 9.44$ & $49.43 \pm 5.90$ \\
$\mathrm{SGR}^{1-10}$ & $19.02 \pm 2.42$ & $20.07 \pm 0.23$ & $18.65 \pm 0.49$ & $19.68 \pm 0.52$ \\
$\mathrm{SGR}^{11-20}$ & $17.68 \pm 0.46$ & $16.80 \pm 1.67$ & $16.77 \pm 1.32$ & $16.47 \pm 1.73$ \\
$\mathrm{SGR}^{21-30}$ & $15.36 \pm 0.20$ & $17.84 \pm 0.88$ & $16.63 \pm 2.18$ & $15.26 \pm 0.15$ \\
$\mathrm{SGR}^{0-30}$ & $17.55 \pm 0.76$ & $18.14 \pm 0.59$ & $17.33 \pm 0.33$ & $17.32 \pm 0.84$ \\
$S$ & $64.7 \pm 5.2$ & $71.1 \pm 8.2$ & $62.6 \pm 8.3$ & $71.6 \pm 10.4$ \\
$C^{0}$ & $34.2 \pm 5.2$ & $28.9 \pm 8.1$ & $35.8 \pm 7.4$ & $26.3 \pm 10.2$ \\
\hline
\end{tabular}

Parameters: superscript values denote the day of experiment; $W=$ body weight $[\mathrm{g}], B=$ fish biomass $[\mathrm{g}], \mathrm{CV}=$ coefficient of variation of body weight [\%], SGR = specific growth rate $\left[\% \cdot\right.$ day $\left.^{-1}\right], S=$ survival at the end of the experiment [\%], $C=$ Mortality caused by both types of cannibalism (type I and type II) [\%]; Values are the mean \pm standard deviations of three replicates; Values in the same a row, marked with different letters differ at $P<0.05$ (one-way ANOVA or Kruskal-Wallis test for CV). 
Linnaeus, 1758 (see Thorpe et al. 1984); brown trout, Salmo trutta Linnaeus, 1758 (see Ojanguren et al. 1996); Atlantic cod, Gadus morhua Linnaeus, 1758 (see Marteinsdottir and Steinarsson 1998); and Siberian sturgeon Acipenser baeri Brandt, 1869 (see Gisbert et al. 2000). In our experiment the egg size did not differ significantly between the four females of European catfish under study, so it is likely that the observed differences in the final growth were rather linked to effects related to environmental factors or yolk characteristics, which can also vary between progenies, but have not been studied here. Several authors concluded that maternal effects could be largely offset by environmental factors, in particular by the food availability (Donelson et al. 2009). Furthermore, it should be reminded that size differences that may emerge during the early life stages could vanish a few months later (Ottesen et al. 2009).

Under culture conditions, cannibalism is the main factor that governs fish survival, especially in larvae and juveniles of fast growing predatory species like the European sea bass (Katavić et al. 1989, Kestemont et al. 2003); vundu catfish, Heterobranchus longifilis Valenciennes, 1840 (see Baras 1999); Eurasian perch, Perca fluviatilis Linnaeus, 1758 (see Baras et. al 2003, Kestemont et al. 2003, Babiak et al. 2004, Mandiki et al. 2007); pikeperch, Sander lucioperca (Linnaeus, 1758) (see Hamza et al. 2007, Szkudlarek and Zakęś 2007, Szczepkowski et al. 2011); barramundi, Lates calcarifer (Bloch, 1790) (see Arockiaraj and Appelbaum 2011); and European catfish (Kozłowski and Poczyczyński 1999, Pruszyński and Pistelok 1999). The results of presently reported study confirmed that cannibalism was the main contributor to the mortality of European catfish larvae and that losses to type II cannibalism outnumbered those to type I cannibalism, as documented in the vast majority of fishes under culture conditions (Braband 1995, Baras 1999, Baras et al. 2000, 2003, Babiak et al. 2004). In our study no maternal influence on cannibalism and survival in European catfish larvae was found. This is possibly because neither the initial body weight of European catfish larvae nor their size heterogeneity differed between progenies here. In other studies, the maternal effects on larval mortality were related to the size dispersal of larvae (Eurasian perch, Babiak et al. 2004; sharptooth catfish, Clarias gariepinus (Burchell, 1822), see Baras and d'Almeida 2001 and Adamek et al. 2011). It cannot be excluded that within a progeny some individuals enjoy greater cannibalistic capacities than others, because of higher growth potential or larger mouth dimensions, thereby accounting for differences between the mortality rates due to cannibalism in different progenies. However, recent studies on the individual performance of siblings have suggested that in fish species with strong cannibalistic tendencies cannibals were "lottery winners rather than natural born killers" (Baras and Lucas 2010, Baras et al. 2014). Therefore, as regards the larviculture of European catfish, cannibalism can presumably be regarded as an alternative feeding strategy, directly or indirectly influenced by environmental factors rather than by genetic components.

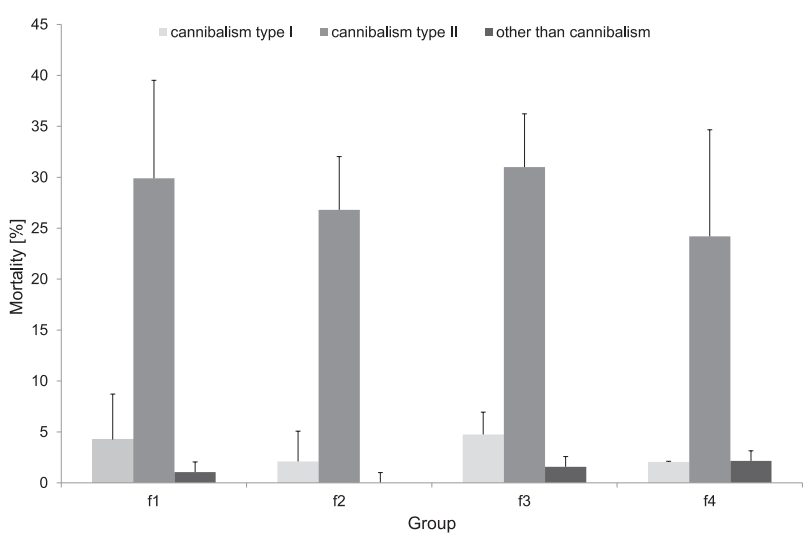

Fig. 1. Respective contributions of incomplete (type I) and complete (type II) cannibalism, and mortality from other causes to the overall mortality rates in experimental groups of larvae of European catfish, Silurus glanis, originating from different females (f1, f2, f3, f4; Experiment 1), after 30 days of rearing; Bars and whiskers are the means and standard deviations of three replicates; No significant differences among groups were found $(P>0.05)$
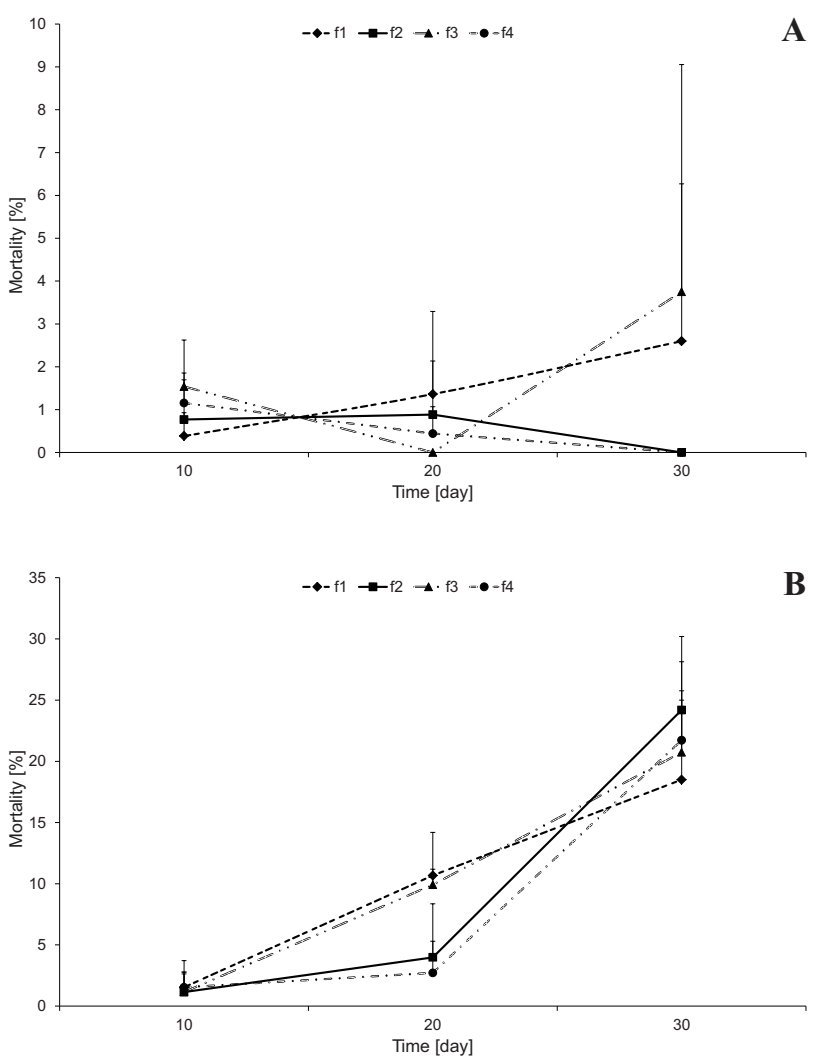

Fig. 2. Dynamics of mortality caused by type I cannibalism (A) and type II cannibalism (B) in experimental groups of larvae of European catfish, Silurus glanis, originated from different females (f1, f2, f3, f4; Experiment 1) during 30 days of rearing; Symbols and whiskers are the means and standard deviations of three replicates; No significant differences among groups were found $(P>0.05)$ 
Effects of tryptophan supplementation. Food availability and quality are the most important factors that govern dominance hierarchies and subsequent size dispersal which can account for the emergence and intensity of cannibalism within a fish cohort (Hecht and Appelbaum 1988, Hecht and Pienaar 1993, Baras and Jobling 2002, Baras 2013). The adjustment of feeding schedules, in terms of food amount, energy content and uniform distribution of food can greatly reduce losses due to cannibalism in intensive culture (Kubitza and Lovshin 1999). Dietary supplementation of tryptophan (TRP) has been shown to reduce aggressive behaviour in several fish species, including the orangespotted grouper, Epinephelus coioides (Hamilton, 1822) (see Hseu et al. 2003); the Atlantic cod (Höglund et al. 2005); the rainbow trout, Oncorhynchus mykiss (Walbaum, 1792) (see Winberg et al. 2001); and an Amazonian characid, Brycon amazonicus (Spix et Agassiz, 1829) (see Wolkers et al. 2012). The aforementioned studies suggested that effects of TRP on the reduction of aggressive behaviour in fish originated from a higher brain serotonin (5-HT) activity. In European catfish larvae, food supplementation with TRP did not result in lower cannibalism. Moreover in the first 10 rearing days the losses caused by type I cannibalism were significantly higher in fish offered food with the highest TRP content, although these differences vanished there- after. As a reminder, TRP is the precursor of 5-HT, which in turn is the precursor of melatonin. If activities of arylalkylamine- $\mathrm{N}$-acetyltransferase and hydroxyindole-Omethyltransferase, the enzymes that are responsible for the conversion of 5-HT to melatonin, are sufficiently high, then an elevated dietary intake of TRP may result in elevated plasma melatonin levels (Lepage et al. 2005a). This further depends on day length, as the production of melatonin is largely inhibited under bright light. In the presently reported study catfish larvae were reared in constant darkness and this could have resulted in a higher production of melatonin, and thus lower concentration of 5-HT than in other studies where the effect of TRP supplementation was evaluated. In the rainbow trout, the effect of elevated dietary TRP on aggressive behaviour does not appear to be mediated by melatonin (Lepage et al. 2005b). However, melatonin has also been reported to affect aggressive behaviour in a cichlid, the blue acara, Aequidens pulcher (Gill, 1858) (see Munro 1986). It is possible that the way 5-HT or melatonin affects aggression varies between fishes (Lepage et al. 2005a).

Effects of TRP supplementation on aggression and dominance hierarchies in fishes can also be mediated by variations in growth, as high levels of serotonin tend to limit food intake and growth in fish (de Pedro et al. 1998,

Table 4

Growth, size dispersal, survival, and mortality caused by cannibalism of larvae of European catfish, Silurus glanis, fed feeds supplemented with tryptophan (Experiment 2) during 30 days of rearing

\begin{tabular}{lccc}
\hline Parameter & & Treatment & T2 \\
\cline { 2 - 3 }$W^{0}$ & T0 & T1 & $0.085 \pm 0.011$ \\
$W^{10}$ & $0.071 \pm 0.007$ & $0.0132 \pm 0.0016$ & $0.35 \pm 0.04$ \\
$W^{20}$ & $0.32 \pm 0.03$ & $0.074 \pm 0.001$ & $1.73 \pm 0.12$ \\
$W^{30}$ & $1.61 \pm 0.06$ & $1.73 \pm 0.08$ & \\
$B^{0}$ & & 1.58 & $7.17 \pm 1.40$ \\
$B^{10}$ & $7.09 \pm 0.68$ & $7.35 \pm 0.13$ & $27.95 \pm 6.83$ \\
$B^{20}$ & $30.39 \pm 1.28$ & $30.67 \pm 4.43$ & $89.31 \pm 5.76$ \\
$B^{30}$ & $81.27 \pm 1.46$ & $92.82 \pm 10.56$ & $22.23 \pm 1.44$ \\
$\mathrm{CV}^{0}$ & & 12.59 & $38.32 \pm 11.68$ \\
$\mathrm{CV}^{10}$ & $22.42 \pm 0.07$ & $21.54 \pm 3.43$ & $40.17 \pm 4.50$ \\
$\mathrm{CV}^{20}$ & $47.27 \pm 8.10$ & $47.70 \pm 4.23$ & $21.31 \pm 1.21$ \\
$\mathrm{CV}^{30}$ & $48.45 \pm 6.07$ & $45.85 \pm 4.64$ & $14.26 \pm 0.17$ \\
$\mathrm{SGR}^{1-10}$ & $19.55 \pm 0.99$ & $19.94 \pm 0.04$ & $15.94 \pm 1.75$ \\
$\mathrm{SGR}^{11-20}$ & $15.15 \pm 2.06$ & $14.92 \pm 1.94$ & $17.16 \pm 0.23$ \\
$\mathrm{SGR}^{21-30}$ & $16.10 \pm 1.41$ & $16.68 \pm 1.50$ & $67.3 \pm 7.0$ \\
$\mathrm{SGR}^{0-30}$ & $16.94 \pm 0.12$ & $17.18 \pm 0.16$ & $28.0 \pm 2.8$ \\
$S^{0}$ & $71.3 \pm 5.9$ & $73.3 \pm 0.8$ & $26.1 \pm 0.2$ \\
$\mathrm{C}^{10}$ & $26.3 \pm 3.4$ & & \\
\hline
\end{tabular}

Parameters: superscript values denote the day of experiment; $W=$ body weight $[\mathrm{g}], B=$ fish biomass $[\mathrm{g}], \mathrm{CV}=$ coefficient of variation of body weight [\%], SGR = specific growth rate $\left[\% \cdot\right.$ day $\left.^{-1}\right], S=$ survival at the end of the experiment $[\%]$, $C=$ Mortality caused by both types of cannibalism (type I and type II) [\%]; Treatment: T0 = without TRP, T1 = $10 \mathrm{~g}$ TRP $\cdot \mathrm{kg}^{-1}, \mathrm{~T} 2=10 \mathrm{~g}$ TRP $\cdot \mathrm{kg}^{-1}$; Values are the mean \pm standard deviations of three replicates. 
Hseu et al. 2003, Papoutsoglou et al 2005a, 2005b). These effects are expectedly higher in the larger fish, presumably the dominant ones, and which can consume a higher proportion of the feed offered (Winberg et al. 2001).

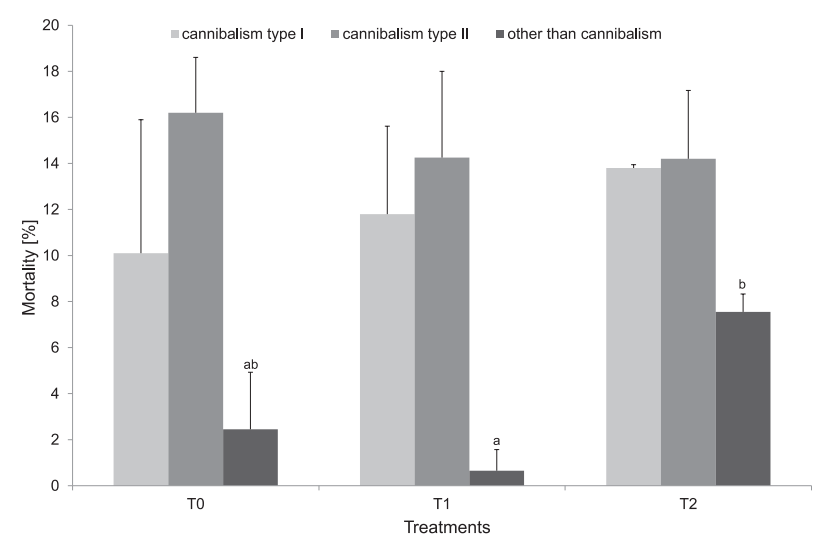

Fig. 3. Respective contributions of incomplete (type I) and complete (type II) cannibalism, and mortality from other causes in larvae of European catfish, Silurus glanis, fed feeds supplemented with tryptophan (T0; T1; T2, Experiment 2) after 30 days of rearing; Bars and whiskers are the means and standard deviations of three replicates; Bars that are marked by the same letter do not differ at $P<0.05$
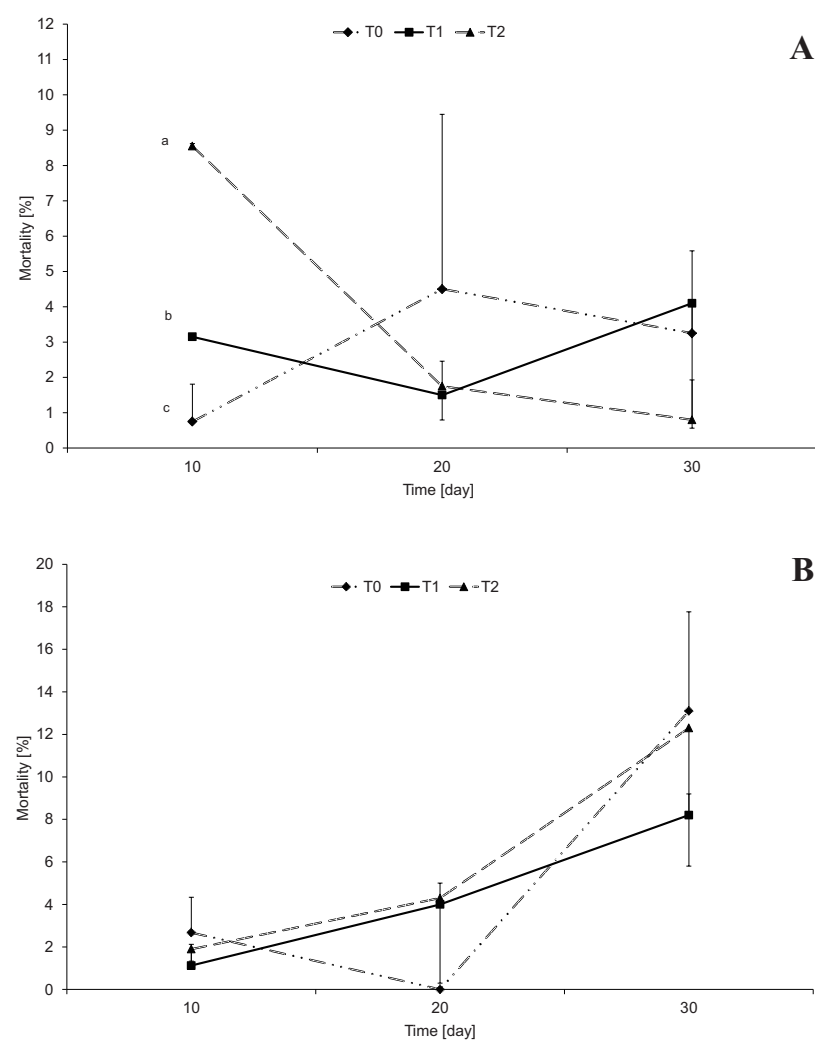

Fig. 4. Dynamics of mortality caused by type I cannibalism (A) and type II cannibalism (B) in experimental groups of larvae of European catfish, Silurus glanis, fed feeds supplemented with tryptophan (T0; T1; T2, Experiment 2) during 30 days of rearing; Values marked with different letters differ at $P<0.05$
However, in contrast to previous studies, there was no effect of TRP supplementation on the growth of European catfish larvae in the presently reported study. Again, this could be due to rearing in darkness, which presumably facilitated the conversion of serotonin into melatonin. This will require further analyses, which are largely beyond the scope of this study.

In conclusion, it is evident that the obtained results demonstrated that both issues: the maternal effect and the TRP-supplemented food did not influence the cannibalism rate and finally the stock survival of catfish larvae. The above-mentioned factors, however, may be equally important for other fish species being cultured. On the other hand, we demonstrated that rearing of European catfish larvae, under controlled conditions, significantly enhanced the survival of juvenile catfish in comparison to traditional culture trials in ponds.

\section{ACKNOWLEDGEMENTS}

This study was financed by the University of Warmia and Mazury in Olsztyn, Poland (project No. 0804.809).

\section{REFERENCES}

Adamek J., Kamler E., Epler P. 2011. Uniform maternal age/size and light restrictions mitigate cannibalism in Clarias gariepinus larvae and juveniles reared under production-like controlled conditions. Aquacultural Engineering 45 (1): 13-19. DOI: 10.1016/j.aquaeng.2011.05.001

Arockiaraj A.J., Appelbaum S. 2011. Sibling cannibalism in juvenile barramundi, Lates calcarifer (Actinopterygii: Perciformes: Centropomidae), reared under different light conditions. Acta Ichthyologica et Piscatoria 41 (1): 7-11. DOI: 10.3750/AIP2011.41.1.02

Babiak I., Mandiki S.N.M., Ratsinjomanana K., Kestemont P. 2004. Initial weight and its variation in post-larval Eurasian perch affect quantitative characteristics of juvenile cohorts under controlled conditions. Aquaculture 243 (1-4): 263-276. DOI: 10.1016/j.aquaculture.2003.12.010

Baras E. 1999. Sibling cannibalism among juvenile vundu under controlled conditions. I. Cannibalistic behaviour, prey selection and prey size selectivity. Journal of Fish Biology 54 (1): 82-105. DOI: 10.1111/j.1095-8649.1999.tb00614.x

Baras E. 2013. Cannibalism in fish larvae: What have we learned? Pp. 31. In: Qin J.G. (ed.) Larval fish aquaculture. Nova Science Publishers, New York, NY, USA.

Baras E., d'Almeida A.F. 2001. Size heterogeneity prevails over kinship in shaping cannibalism among larvae of sharptooth catfish Clarias gariepinus. Aquatic Living Resources 14 (4): 251-256. DOI: 10.1016/S0990-7440(01)01118-4

Baras E., Hafsaridewi R., Slembrouck J., Priyadi A., Moreau Y., Pouyaud L. 2014. Do cannibalistic fish possess an intrinsic higher growth capacity than others? A case study in the Asian redtail catfish Hemibagrus nemurus (Valenciennes, 1840). Aquaculture Research 45 (1): 68-79. DOI: $10.1111 / j .1365-2109.2012 .03205 . x$

Baras E., Jobling M. 2002. Dynamics of intracohort cannibalism in cultured fish. Aquaculture Research 33 (7): 461-479. DOI: 10.1046/j.1365-2109.2002.00732.x 
Baras E., Kestemont P., Mélard C. 2003. Effect of stocking density on the dynamics of cannibalism in sibling larvae of Perca fluviatilis under controlled conditions. Aquaculture 219 (1-4): 241-255. DOI: 10.1016/S0044-8486(02)00349-6

Baras E., Lucas M.C. 2010. Individual growth trajectories of sibling Brycon moorei raised in isolation since egg stage, and their relationship with aggressive behaviour. Journal of Fish Biology 77 (4): 985-997. DOI: 10.1111/j.10958649.2010.02740.x

Baras E., Ndao M., Maxi M.Y.J., Jeandrain D., Thome J.P., Vandewalle P., Mélard C. 2000. Sibling cannibalism in dorada under experimental conditions. I. Ontogeny, dynamics, bioenergetics of cannibalism and prey size selectivity. Journal of Fish Biology 57 (4): 1001-1020. DOI: 10.1111/j.1095-8649.2000.tb02207.x

Braband A. 1995. Intra-cohort cannibalism among larval stages of perch (Perca fluviatilis). Ecology of Freshwater Fish 4 (2): 70-76. DOI: 10.1111/j.1600-0633.1995.tb00119.x

Butts I.A.E., Litvak M.K. 2007. Parental and stock effects on larval growth and survival to metamorphosis in winter flounder (Pseudopleuronectes americanus). Aquaculture 269 (1-4): 339-348. DOI: 10.1016/j.aquaculture.2007. 04.012

Cuff W.R. 1980. Behavioral aspects of cannibalism in larval walleye, Stizostedion vitreum. Canadian Journal of Zoology 58 (8): 1504-1507. DOI: 10.1139/z80-207

de Pedro N., Pinillos M.L., Valenciano A.I., Alonso-Bedate M., Delgardo M.J. 1998. Inhibitory effect of serotonin on feeding behavior in goldfish: Involvement of CRF. Peptides 19 (3): 505-511. DOI: 10.1016/S0196-9781(97)00469-5

Donelson J.M., Munday P.L., McCormick M.I. 2009. Parental effects on offspring life histories: when are they important? Biology Letters 5 (2): 262-265. DOI: 10.1098/rsbl.2008.0642

Gisbert E., Williot P., Castelló-Orvay F. 2000. Influence of egg size on growth and survival of early stages of Siberian sturgeon (Acipenser baeri) under small scale hatchery conditions. Aquaculture 183 (1-2): 83-94. DOI: 10.1016/S0044-8486(99)00287-2

Hamza N., Mhetli M., Kestemont P. 2007. Effects of weaning age and diets on ontogeny of digestive activities and structures of pikeperch (Sander lucioperca) larvae. Fish Physiology and Biochemistry 33 (2): 121-133. DOI: 10.1007/s10695-006-9123-4

Hecht T., Appelbaum S. 1988. Observations on intraspecific aggression and coeval sibling cannibalism by larval and juvenile Clarias gariepinus (Clariidae: Pisces) under controlled conditions. Journal of Zoology 214 (1): 21-44. DOI: 10.1111/j.1469-7998.1988.tb04984.x

Hecht T., Pienaar A.G. 1993. A review of cannibalism and its implications in fish larviculture. Journal of the World Aquaculture Society 24 (2): 246-261. DOI: 10.1111/j.17497345.1993.tb00014.x

Höglund E., Bakke M.J., Øverli Ø., Winberg S., Nilsson G.E. 2005. Suppression of aggressive behaviour in juvenile Atlantic cod (Gadus morhua) by L-tryptophan supplementation. Aquaculture 249 (1-4): 525-531. DOI: 10.1016/j.aquaculture.2005.04.028
Hseu J.R., Lu F.I., Su H.M., Wang L.S., Tsai C.L., Hwang P.P. 2003. Effect of exogenous tryptophan on cannibalism, survival and growth in juvenile grouper, Epinephelus coioides. Aquaculture 218 (1-4): 251-263. DOI: 10.1016/S00448486(02)00503-3

Johnston W.L., Atkinson J.L., Hilton J.W., Were K.E. 1990. Effect of dietary tryptophan on plasma and brain tryptophan, brain serotonin, and brain 5-hydroxyindoleacetic acid in rainbow trout. Journal of Nutritional Biochemistry 1 (1): 49-54. DOI: 10.1016/0955-2863(90)90100-Y

Katavić I., Jug-Dujaković J., Glamuzina B. 1989. Cannibalism as a factor affecting the survival of intensively cultured sea bass (Dicentrarchus labrax) fingerlings. Aquaculture 77 (2-3): 135-143. DOI: 10.1016/00448486(89)90197-X

Kestemont P., Jourdan S., Houbart M., Mélard C., Paspatis M., Fontaine P., Cuvier A., Kentouri M., Baras E. 2003. Size heterogeneity, cannibalism and competition in cultured predatory fish larvae: biotic and abiotic influences. Aquaculture 227 (1-4): 333-356. DOI: 10.1016/S00448486(03)00513-1

Kozłowski J., Poczyczyński P. 1999. The effect of light and stocking density on the results of rearing of European catfish (Silurus glanis L.) larvae. Archives of Polish Fisheries 7 (2): 297-306.

Kubitza F., Lovshin L.L. 1999. Formulated diets, feeding strategies, and cannibalism during intensive culture of juvenile carnivorous fishes. Reviews in Fisheries Science 7 (1): 1-22. DOI: 10.1080/10641269991319171

Lepage O., Larson E.T., Mayer I., Winberg S. 2005a. Tryptophan affects both gastrointestinal melatonin production and interrenal activity in stressed and nonstressed rainbow trout. Journal of Pineal Research 38 (4): 264-271. DOI: 10.1111/j.1600-079X.2004.00201.X

Lepage O., Larson E.T., Mayer I., Winberg S. 2005b. Serotonin, but not melatonin, plays a role in shaping dominant-subordinate relationships and aggression in rainbow trout. Hormones and Behavior 48 (2): 233-242. DOI: 10.1016/j.yhbeh.2005.02.012

Lepage O., Tottmar O., Winberg S. 2002. Elevated dietary intake of L-tryptophan counteracts the stress-induced elevation of plasma cortisol in rainbow trout (Oncorhynchus mykiss). Journal of Experimental Biology 205 (23): 3679-3687.

Linhart O., Štěch L., Švarc J., Rodina M., Audebert J.P., Grecu J., Billard R. 2002. The culture of the European catfish, Silurus glanis, in the Czech Republic and in France. Aquatic Living Resources 15 (2): 139-144. DOI: 10.1016/S0990-7440(02)01153-1

Loadman N.L., Moodie G.E.E., Mathias J.A. 1986. Significance of cannibalism in larval walleye (Stizostedion vitreum). Canadian Journal of Fisheries and Aquatic Sciences 43 (3): 613-618. DOI: 10.1139/f86-073

Mandiki S.N.M., Babiak I., Krol J., Rasolo J.F.R., Kestemont P. 2007. How initial predator-prey ratio affects intra-cohort cannibalism and growth in Eurasian perch Perca fluviatis L larvae and juveniles under controlled conditions. Aquaculture 268 (1-4): 149-155. DOI: 10.1016/j.aquaculture.2007.04.036 
Marteinsdottir G., Steinarsson A. 1998. Maternal influence on the size and viability of Iceland cod Gadus morhua eggs and larvae. Journal of Fish Biology 52 (6): 1241-1258. DOI: 10.1111/j.1095-8649.1998.tb00969.x

Munro A.D. 1986. Effects of melatonin, serotonin, and naloxone on aggression in isolated cichlid fish (Aequidens pulcher). Journal of Pineal Research 3 (3): 257-262. DOI: 10.1111/j.1600-079X.1986.tb00748.x

Nuñez J., Castro D., Fernández C., Dugué R., Chu-Koo F., Duponchelle F., García C., Renno J.F. 2011. Hatching rate and larval growth variations in Pseudoplatystoma punctifer: maternal and paternal effects. Aquaculture Research 42 (6): 764-775. DOI: 10.1111/j.1365-2109.2011.02803.x

Ojanguren A.F., Reyes-Gavilán F.G., Braña F. 1996. Effects of egg size on offspring development and fitness in brown trout, Salmo trutta L. Aquaculture 147 (1-2): 9-20. DOI: 10.1016/S0044-8486(96)01398-1

Ottesen O.H., Babiak I. 2007. Parental effects on fertilization and hatching success and development of Atlantic halibut (Hippoglossus hippoglossus L.) embryos and larvae. Theriogenology $\mathbf{6 8}$ (9): 1219-1227. DOI: 10.1016/j.theriogenology.2007.08.015

Ottesen O.H., Babiak I., Dahle G. 2009. Sperm competition and fertilization success of Atlantic halibut (Hippoglossus hippoglossus L.). Aquaculture 286 (3-4): 240-245. DOI: 10.1016/j.aquaculture.2008.09.018

Panagiotaki P., Geffen A.J. 1992. Parental effect on size variation in fish larvae. Journal of Fish Biology. 41 (Suppl. sB): 37-42. DOI: 10.1111/j.1095-8649.1992.tb03866.x

Papoutsoglou S.E., Karakatsouli N., Chiras G. 2005a. Dietary L-tryptophan and tank colour effects on growth performance of rainbow trout (Oncorhynchus mykiss) juveniles reared in a recirculating water system. Aquacultural Engineering 32 (2): 277-284. DOI: 10.1016/j.aquaeng.2004. 04.004

Papoutsoglou S.E., Karakatsouli N., Koustas P. 2005 b. Effects of dietary L-tryptophan and lighting conditions on growth performance of European sea bass (Dicentrarchus labrax) juveniles reared in a recirculating water system. Journal of Applied Ichthyology 21 (6): 520-524. DOI: 10.1111/j.1439-0426.2005.00664.x

Pruszyński T., Pistelok F. 1999. Biological and economical evaluation of African and European catfish rearing in water recirculation systems. Archives of Polish Fisheries 7 (2): 343-352.

Saillant E., Chatain B., Fostier A., Przybyla C., Fauvel C. 2001. Parental influence on early development in the European sea bass. Journal of Fish Biology 58 (6): 1585-1600. DOI: 10.1111/j.1095-8649.2001.tb02314.x

Szkudlarek M., Zakęś Z. 2007. Effect of stocking density on survival and growth performance of pikeperch, Sander lucioperca (L.), larvae under controlled conditions. Aquaculture International 15 (1): 67-81. DOI: 10.1007/ s10499-006-9069-7

Szczepkowski M., Zakęś Z., Szczepkowska B., Piotrowska I. 2011. Effect of size sorting on the survival, growth and cannibalism in pikeperch (Sander lucioperca L.) larvae during intensive culture in RAS. Czech Journal of Animal Science 56 (11): 483-489.

Svenning M.A., Borgstrøm R. 2005. Cannibalism in Arctic charr: do all individuals have the same propensity to be cannibals? Journal of Fish Biology 66 (4): 957-965. DOI: 10.1111/j.0022-1112.2005.00646.x

Thibault R.E. 1974. Genetics of cannibalism in a viviparous fish and its relationship to population density. Nature 251 (5471): 138-140. DOI: 10.1038/251138a0

Thorpe J.E., Miles M.S., Keay D.S. 1984. Developmental rate, fecundity and egg size in Atlantic salmon, Salmo salar L. Aquaculture 43 (1-3): 289-305. DOI: 10.1016/00448486(84)90030-9

Ulikowski D., Borkowska I. 1999. The effect of initial stocking density on growth of European catfish (Silurus glanis L.) larvae under controlled conditions. Archives of Polish Fisheries 7 (1): 151-160.

Winberg S., Øveril Ø., Lepage O. 2001. Suppression of aggression in rainbow trout (Oncorhynchus mykiss) by dietary L-tryptophan. Journal of Experimental Biology 204 (22): 3867-3876.

Wolkers C.P.B., Serra M., Hoshiba M.A., Urbinati E.C. 2012. Dietary L-tryptophan alters aggression in juvenile matrinxã Brycon amazonicus. Fish Physiology and Biochemistry 38 (3): 819-827. DOI: $10.1007 / \mathrm{s} 10695-011-9569-\mathrm{x}$

Received: 8 March 2014

Accepted: 2 June 2014

Published electronically: 15 October 2014 